\title{
NEUROLOGICAL LETTER FROM TURKEY
}

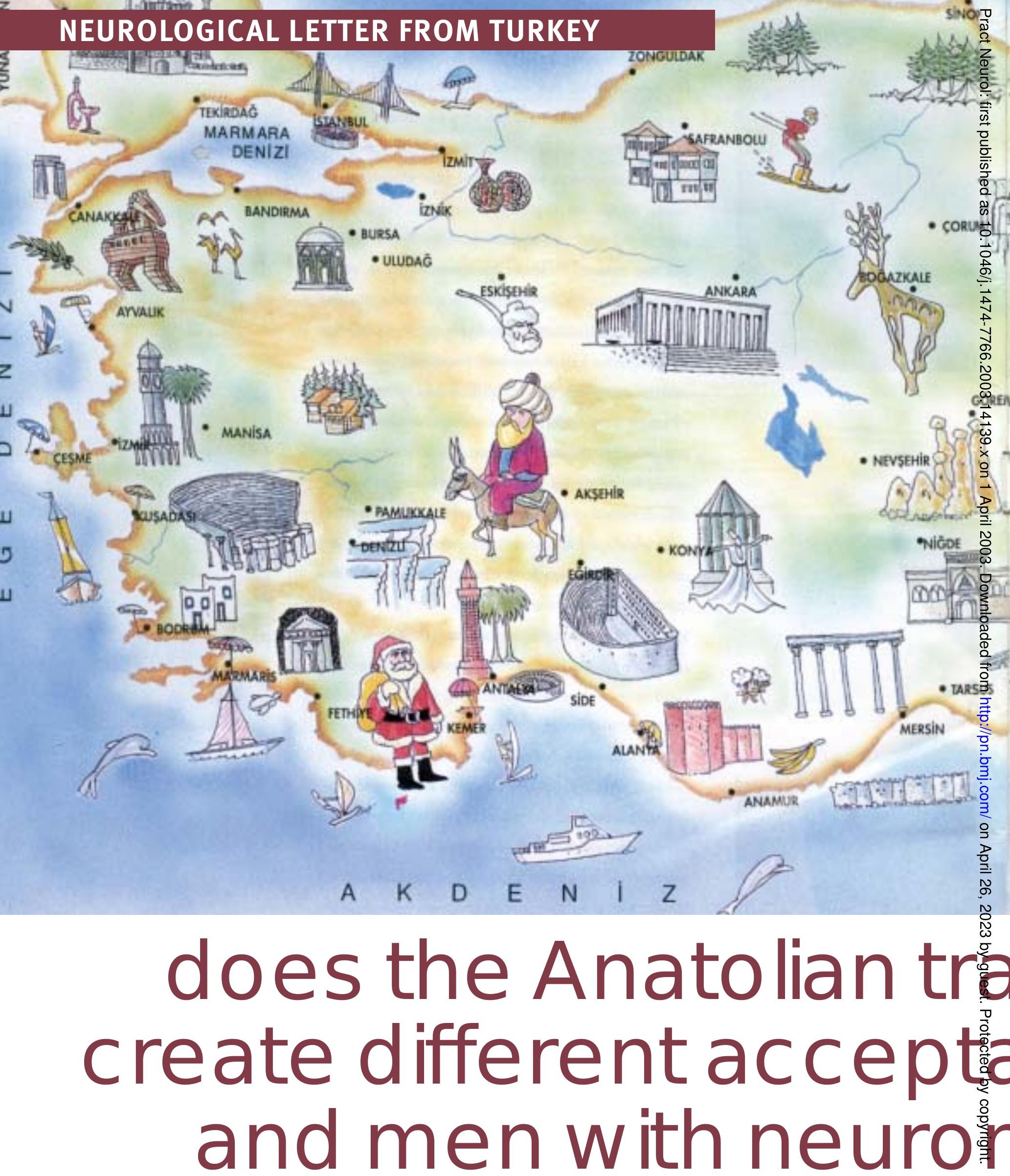


D. D $E N \mid Z$

TOKAT

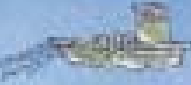

\section{GÜRCISTAN}
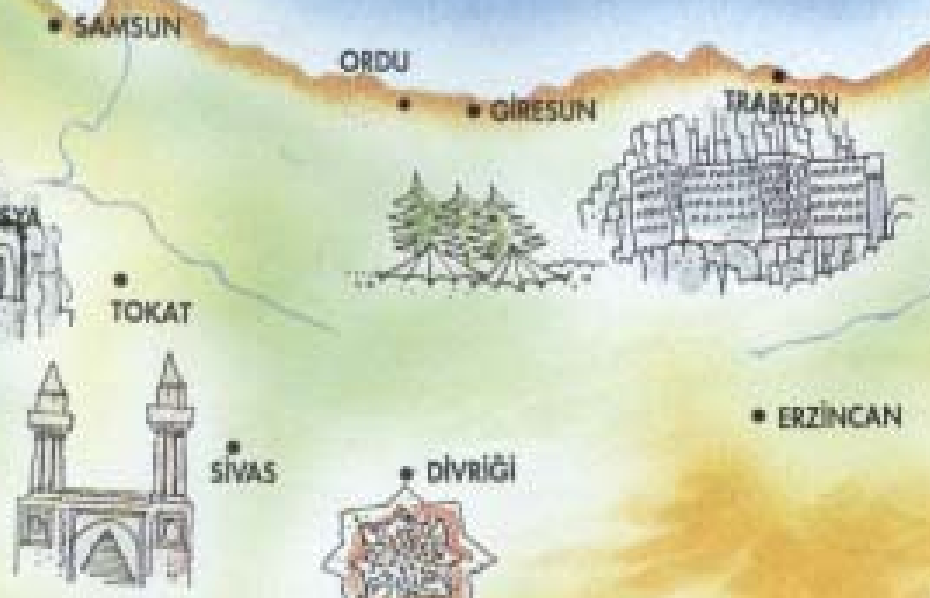

- karseri

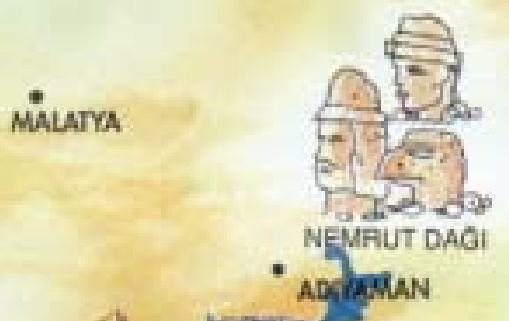

- erzincan
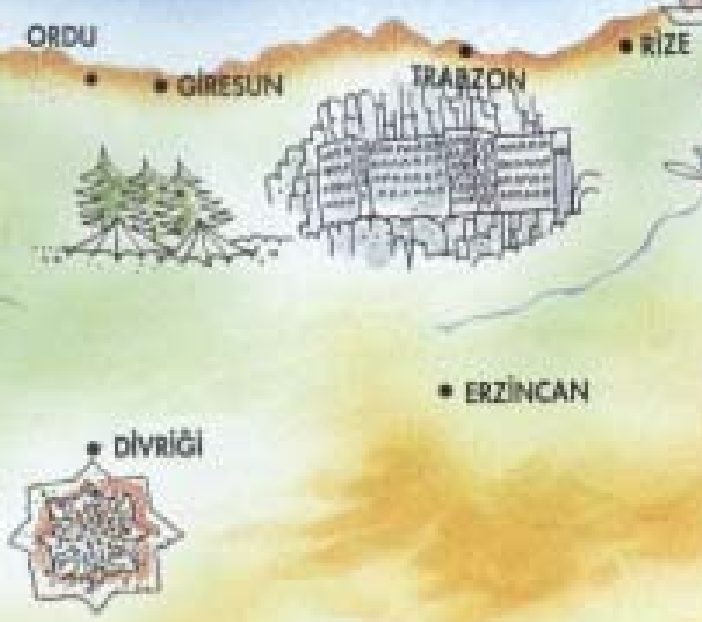

HOPA

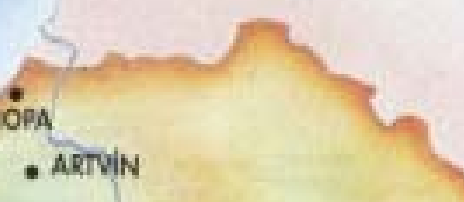

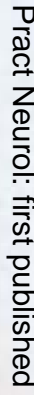

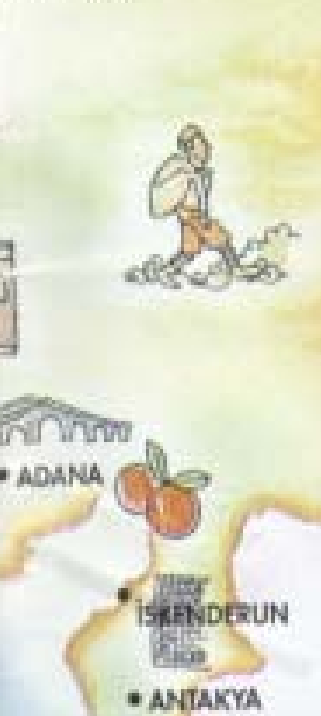

- antakra

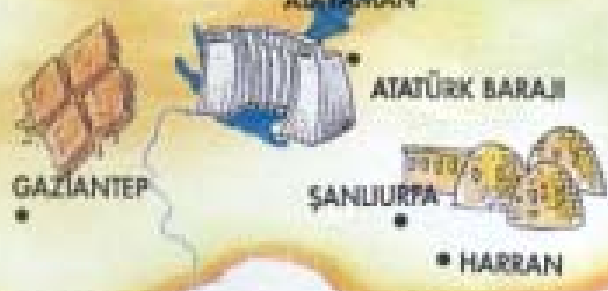

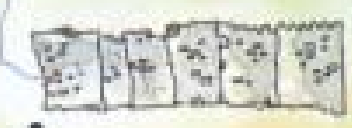
oirangakia

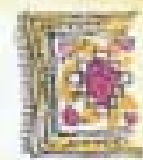

Piraye Serdarodlu pirayes@hotmail.com

Practical Neurology, 3, 118-121

\section{ditio nal family system}

\section{nce patterns in women} uscular conditions? 


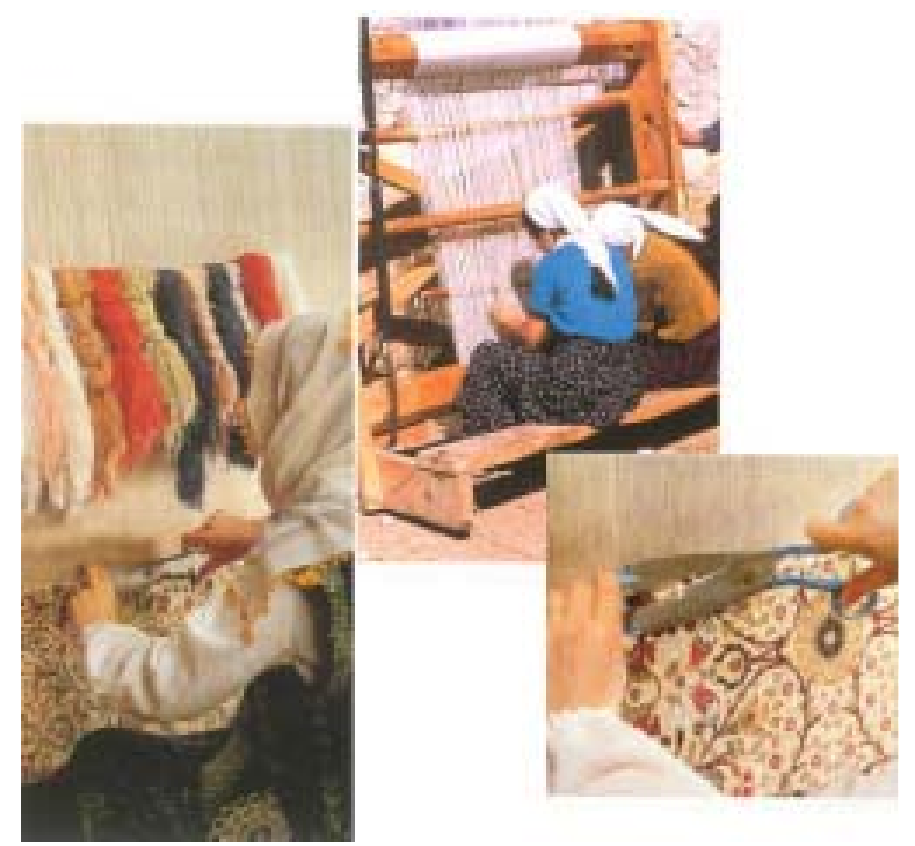

A natolia is a land of contrasts. Sun and snow, the rough Black Sea and vivid but peaceful Mediterranean, old and new, traditional and modern traits all determine its colourful nature and lifestyle. And it has been the cradle of many cultures, civilizations and religions. The latest state founded on Anatolia, sometimes known as the peninsula of Asia $M$ inor, is the republic of Turkey, which also annexed asmall part of Europeto itself and so isthe only country spanning two continents.

The vast majority of the population in the Republic of Turkey isM uslim, therest areChristian and Jewish. But Anatolia, with its amalgam of cultures, hasauniqueand mild interpretation of Islam, which is reflected in its social life. The effects of religion and theremnants of premodern society in rural areas, as well as in the suburbs of big cities, encourages large families with their traditions. This social structureis mingled with the modern life of urban areas where the nuclear family is the norm, especially in the western parts of the country. Combination of west and east, the fusion of conservative and new, creates the prevailing life style.

The large conservative family system brings its own values and traditions to all aspects of everyday life. The individual blends his or her morals and customs with those of the family. The boundary of individuals is blurred and, when making decisions, they have to take into account the essentials of the whole family. Al- though this may have a negative impact on the life of the individual, it enhances the spirit of mutual support within thefamily, which is also mirrored in society. This is unliketheorganization of the nuclear family of modern society where the limits of each individual - although still slightly different for women and men - are quite clear, giving the possibility for freer and more autonomous decision making, but at the same time bringing responsibility to oneself and a feeling of loneliness. In my opinion, this difference, within the context of the advantages and disadvantages of both family systems, isone of the reasons why dissimilar societies should have differently organized social structures. When patient care facilities are considered, this becomes more important because 'caring' itself refers to the feeling and attitude of the individual as well as the approach of other people within the community, which is determined by the tendencies, practices and customs of that society.

The way children are brought up - although mingled with the customs of modern life - is conservative and traditional in most families in Anatolia. Relevant to the practice of neurology, one of the features of this custom is the difference between raising females and males, which is much bigger than in the nuclear families of western societies. This magnifies the genderbased difference, which al ready existsin all types of societies, in the acceptance of conditions that affect mobility, such as neuromuscular disorders.

Girls start taking their position within the patriarchal family moral values system even in the early years of life. They are prepared to be virtuous, decent and domestic, to be compatible with the moral practice of the family. They are encouraged to play in the house with domestic toys but more importantly to be demure, modestand to sit still. On theother hand, boys are encouraged to be outgoing, social and active- to run, jump and fight during play. They definitely have to be educated and the undereducation in our country is mainly a problem for girls rather than boys. This traditional style of upbringing, mainly influenced by the Islamic culture, continues during adolescence. This is when Islamic influence begins to be felt by the female sex. Sanity and sobriety are expected to be the main features of a woman in this transitional period. It is important to give the adolescent girl the values of being quiet, domestic and chasteas she prepares to become 
a woman. She should deal with housekeeping tasks. As she gets older, life moves even more into the house. Social life is usually limited to mixing with female relatives and the women of the neighbourhood. Values of women, and gaining feminine experience, are learned from the older women within this community. Toys change to handcrafts, which are a preparation for the wedding and the new house of the future. School education is quite secondary. Boys at a similar age start going out and learn the ways of sociability. Social life outside the house isimportant to them. They go to school or they work outside the house.

After marriage, women get the opportunity to put into practice within their own house the domestic tasks they havelearned. Thenecessary tasks, care of the children and the husband are again limited to thehouse. Thehouseisthemain place of activity for women; it is by far the biggest part of their everyday life. Thisgives women a freedom of creativity within their house. The woman's loose self boundary is framed by the boundary of her home. An outsidejob, if shehas one, is almost al ways a secondary task.

What effects do thesetraditional or conservative traits have on people with neuromuscular disorders, which are probably similar in their effect to many other conditions that affect mobility? Aremen and women affected differently? Naturally, being a disabled woman has the expected consequences of progressively changing body image and feeling insecure in the definition of 'beautiful', problems in carrying a baby and so on.

However, one consequence of raising children in a conservative family setting surprised me, when I realized it. Compared with the world of active men whose physical strength is frequently being tested, who are expected to be educated and to have a job - inevitably outside the house - just being a woman creates an amazing and natural adaptation to any condition that limits mobility. A boy or a man has to go out, walk long distances or run, get on buses. In a myopathic process, usually the first affected muscles are the very ones he uses for his everyday activities. Themobility of men and women may be affected similarly but the negative consequences on everyday living becomes evident very early in men. They become more introverted as they lose their mobility, they can't go out so easily. But the house is not their field of interest, it is traditionally the area of women. This creates loss of status, which is the main reason for being unable to accept their condition, and this creates loss of selfconfidence. Women, on theother hand, arealso unable to go out and are destined to remain in the house. However, they are still within the framework in which they can use their creativity. A woman may have difficulty because of her proximal weakness, of course, but she can cope with it by hand-made creations that she has learned throughout her life. As most myopathies affect the legs first, women can use their hands until very late and maintain their creativity. M any of our female patients show us beautiful examples of knitting, lacework and cooking, which give them a feeling of satisfaction rather than uselessness.

Paradoxically, in this setting, although the woman is 'disabled', she has the environment to copewith her situation - sheisnothandicapped liketheman with the samedisability.

\section{EDITORIAL COMMENT}

These thoughts are not just helpful in Turkey but should have a resonance anywhere in the world where neurologists are called to treat people from different cultures and traditions. I now understand better thefeelings of aPakistani patient with epilepsy, unable to work and confined to his home as a result. $\mathrm{H}$ is wife goes out to work, brings him to the clinic and speaks far better English. H isstatus has been undermined, and no wonder heis depressed.

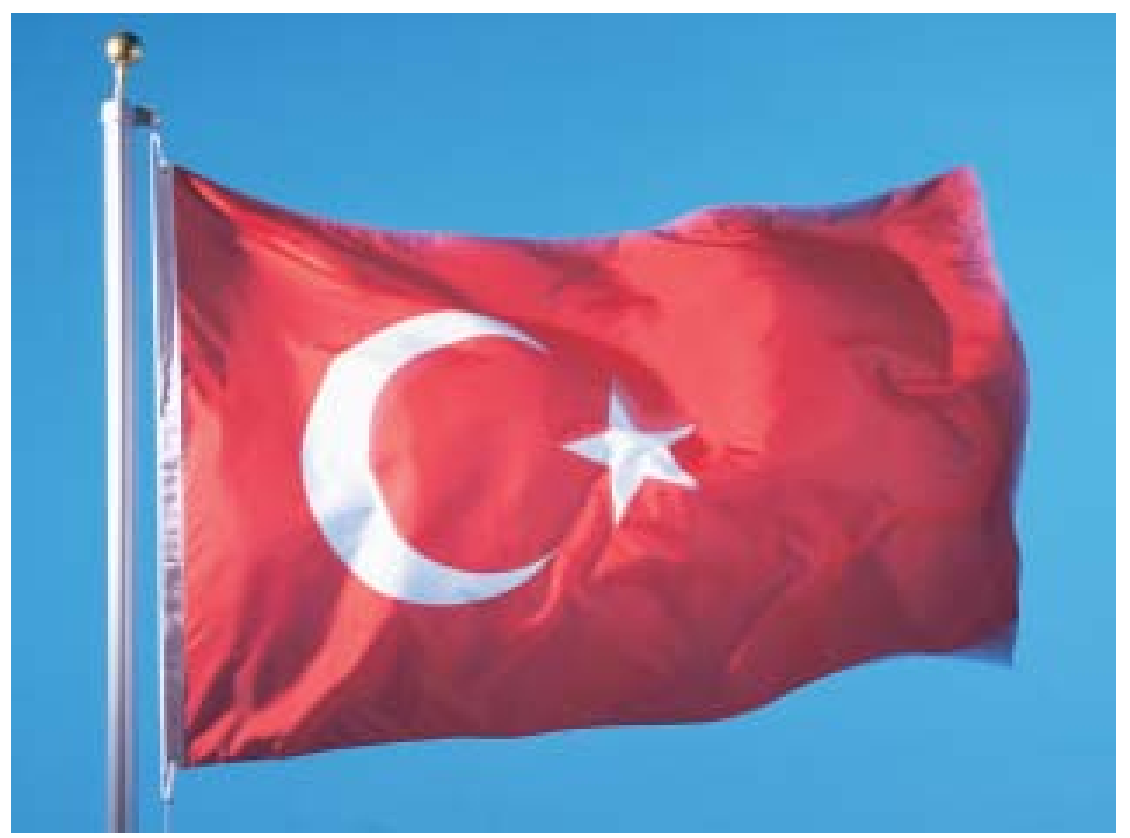

